\title{
The use of an interactive music system as an aid for exploring sound in music education in a rural area
}

\author{
Mario Alberto Duarte-García ${ }^{1}$, \\ Emma Wilde ${ }^{1}$, \\ Rodrigo Cortez-Madrigal ${ }^{1}$, \\ Jorge Rodrigo Sigal-Sefchovich ${ }^{1,2}$ \\ ${ }^{1}$ The National Autonomous University of Mexico, UNAM. \\ mduarte@enesmorelia.unam.mx \\ ${ }^{2}$ Mexican Centre for Music and Sonic Arts, CMMAS. \\ rodrigo@cmmas.org
}

\begin{abstract}
Technology has been widely used for educational processes; in the arts several researchers have investigated the employment of computational systems and gadgets to approach younger audiences. This paper describes the design and implementation of an interactive music system used as a tool for an electroacoustic music course for children in a rural community. The system comprises a MaxMSP digital interface and an OSC Controller app for Android. Graphic User Interfaces were created in MaxMSP in order to process individual musical parameters, this can be controlled by mobile devices using Open Sound Control OSC protocols. The interactive system was used by children (6-15 years old) to explore sound worlds during a series of electroacoustic music courses and workshops.
\end{abstract}

Keywords: interactive music systems, sound mobile apps, electroacoustic music, music educational program, socially underserved communities.

\section{El uso de un sistema de música interactivo como ayuda para explorar el sonido en la educación musical en un área rural}

Resumen: La tecnología ha sido ampliamente utilizada con fines educativos; en el ámbito artístico, diversos estudiosos han empleado dispositivos móviles y sistemas computacionales para acercase a las audiencias más jóvenes. Este artículo describe el diseño y la implementación de un sistema musical interactivo como herramienta educativa, fue utilizada en un curso enfocado en el estudio de la música electroacústica en una comunidad rural. El sistema interactivo se integró por una interfaz digital en MaxMSP y un Controlador OSC en una aplicación para Android. Las interfaces gráficas de usuario en MaxMSP sirven para procesar diferentes parámetros musicales que pueden ser controlados por medio de la aplicación móvil por medio de protocolos OSC. El sistema interactivo fue utilizado en un curso educativo por estudiantes de primaria y secundaria (6-15 años), con el objetivo de explorar el sonido en una serie de cursos y talleres de electroacústica.

Palabras Clave: Sistema musical interactivo, aplicaciones móviles para el sonido, música electroacústica, programa educativo musical, comunidades en desventaja social.

\section{Introduction}

The evolution of technology has allowed for the development of hardware and software at affordable prices which means that not only specialized musicians have access 
to such technology. Now people from different age groups, especially younger people, can access technology for the purposes of music creation. Interactive music systems have changed the way in which musicians are involved in the making music process and more people are engaging with music at earlier stages of their lives. Younger children have a very natural approach to technology, and this can be taken advantage of to create strategies for teaching electroacoustic music at elementary levels of education.

The use of music technology in the classroom has been widely explored by several researchers; Manzo (2007) developed an open source application to assist teachers in delivering performance and composition lessons through the use of an interactive music system called EAMIR ${ }^{1}$. Additionally, Manzo (2011) wrote a book to guide teachers and students in the development of interactive music systems for educative creative processes (Max/MSP/Jitter for Music). LaRose, Burns \& Chupka (2014) used a motion tracking application to teach music composition to children with special needs in elementary schools. Moreover, Masu et al (2017) designed an interactive system called Robinflock to generate and manipulate different musical parameters in real time in order to allow children to create polyphonic compositions. Robinflock stimulated children to participate in the compositional process. Tobias (2018) argues that the use of digital media and new technology provides students with opportunities to engage with music through a "new literacy" that new forms of media brings into account and this must be regarded in the development of music education programs.

All these projects suggest that the use of music technology in the classroom has a potential to bring young students into music fields and can provide an important opportunity in the development of creativity in children as well as a pedagogical tool for teachers in the delivering of their music teaching.

Around the world there are various examples of educative programs related to music and education. We can mention the holistic pedagogical work in the UK of Leigh Landy (2012) Making Music with Sounds, which is a fundamental text to approach to sound-based music composition. This book is reinforced by Landy's online pedagogical ElectroAcoustic Resource Site EARS II. Another example is Eersteklasconcerten by Musica, Impulse Centre for Music in Belgium. In this program primary school children

\footnotetext{
${ }^{1}$ http://www.eamir.org
} 
attend a music hall for one day and interact with different ensembles and performers, this activity introduces the children to contemporary instrumental music (Regenmortel, 2017: 93). There have been some efforts to promote access to electroacoustic music in Mexico; for example, the Mexican Centre for Music and Sonic Arts CMMAS in Morelia, has been developing the program Acercamientos Sonoros ${ }^{2}$ (sound encounters) since 2015. The main aim of this program is to reduce the distance between the creation of electroacoustic music and the public, as well as to arouse the interest of children and teenagers in music created or performed with new technologies. It is fair to also mention that many independent artists have worked in various non-institutional initiatives involving electroacoustic that go beyond the scope of this text.

The educative programs described above are mainly set in cities. The study of electroacoustic music in schools located in rural areas of Mexico has been little explored. This research investigated the use of an interactive music system as an educative tool, using a mobile phone app which controls a graphic user interface in MaxMSP through OSC communication. This tool was used in a pedagogical program in a rural community in Michoacán, Mexico.

\section{Community Background}

The town of Tumbisca is located 35 kilometers from Morelia in the middle of the mountains of the Trans-Mexican Volcanic belt. The main economic activities are related to woodcutting, sap extraction from trees, beekeeping and mezcal production. This locality has around 200 inhabitants, Tumbisca has a high level of social disadvantage and marginalization compared with the national average (INEGI, 2005). The community does not have access to technological communications such as broadband internet, fixed landline connections or computers. All these services are substituted by mobile devices and smartphones.

A quarter of the population are children aged from 5 to 15 years old. There are 40 children that attend the primary school which has only one teacher, and three teachers deliver the lessons to 20 adolescents in the secondary school. There is a lack of artistic subjects offered in the schools although these are a compulsory part of the national

\footnotetext{
${ }^{2} \mathrm{http}: / / \mathrm{cmmas}$. org/as/
} 
curriculum for basic education. The teaching staff is not artistically specialized; in consequence they have to look for other kinds of activities in order to fulfill the curriculum. The educative program was implemented in Tumbisca due to the social features described above and the willingness of the community to participate in this project.

\section{National Arts Curriculum Content for Basic Education}

The Mexican Public Ministry of Education stipulates that children in primary schools should receive 1 hour of artistic education per week whereas students in secondary level need to have at least 3 hours of artistic training (SEP, 2017). In the same document, the Ministry leaves open the options depending on the teaching staff availability and there is a choice of artistic fields to be studied which includes music, theatre, fine arts or dance. Additionally, the document establishes general competences and skills for all the arts sharing same pedagogical objectives in primary and secondary levels at a different depth. The study of arts is divided into four areas:

1. Artistic practice: To develop an artistic project.

2. Basic elements: To study the basic elements of music (music parameters).

3. Expression and creativity: To create an artistic work.

4. Arts and environment: To promote artistic and social relationships between the art and the community.

As we see above, all these areas can be addressed by different approaches depending on the school's resources and teaching staff availability.

The teachers of Tumbisca have been very active with trying to get artists and NGOs from the region to deliver these four areas described above. The main issue with this approach is that some artists and NGOs involved only go to the community to deliver concerts, exhibitions or workshops one to three times per year depending on the commitment and budget of the organization. The strategy employed by some NGOs is to do one single workshop in one community in order to reach more people and more 
localities. Although, this strategy is understandable due to fact that they need to show figures to sponsors or government in order to get funding, this policy does not solve the educational lagging in the community. The amount of time employed does not meet the criteria of the minimal time framework stated by the Public Ministry of Education in the National Arts Curriculum and these activities are only focused on one or two of the four areas of artistic study stated above.

To solve the artistic educational lagging problem, it is necessary to consider the continuity of artistic activities in a school and not only the quantity of people that can be reached in one single time. The Music Maze program ${ }^{3}$ by Birmingham Contemporary Music Group addressed this kind of problem; they deliver a series of workshops on Sundays about once a month for one year. The program is aimed at children aged from 8 to 11 years old. The workshops are an opportunity to play or start to play an instrument as well as start to create music; at the end of the year children have a concert for family and friends. An implementation of a program like Music Maze in Tumbisca would require a large amount of funding, resources and infrastructure that Tumbisca does not have. We tried to contribute to music education, addressing the educational lagging problem with the help of music technology in order to fulfill the four areas described above throughout the study of electroacoustic music using a very basic configuration of an interactive music system. In this sense we believe that our research can contribute to the mitigation of the music educational lagging problem. The tools created for this research will be described below.

\section{Interactive Music Systems}

A system has been defined by Backlund (2000) as an array of elements that are interconnected to achieve a goal; each element in the system is affected by the response of the others. According to Manzo (2011) an interactive music system is a set of hardware/software arrangements that is designed to manage a musical task in real-time; it has mainly been associated with accomplishing performance and compositional objectives. Interactive music systems propose an active way of engaging with music where children can explore musical parameters through interactions with computers or

\footnotetext{
${ }^{3}$ https://www.bcmg.org.uk/music-maze
} 
gadgets. An interactive system is generally integrated by a computer and physical/digital interfaces. The computer is the musical brain of the system; it can analyze, process and transform the sound, while the interface bridges the physical world with the digital. These input devices can convert gestures, movements and actions into computer data code (Winkler, 1995, p. 4). As stated above, human actions captured by the interfaces can modify the sound using computer programs, the elements of the interactive systems are interrelated, and the actions affect the response of the other components in the system.

Interfaces have undergone a significant development during the last decades, midi controllers marked an important step in facilitating the spread of electronic music, the use of these physical devices for performance and composition allowed for the development of interactive music systems and more people started to incorporate new technology as a source of musical configurations, developing the interaction between musicians and computer music. In this sense, interactive systems helped to 'establish a common language for both technological and musical invention' (Boulez, 1986, p. 10). Smart devices brought about a second revolution in the development of interactive systems, digital interfaces can be downloaded in just seconds, having the advantage of a quick and economic access compared to a physical interface. Digital interfaces and apps can be modified and edited according to creative/artistic needs; also, they can be taken everywhere and connected wirelessly through WIFI access using an OSC protocol.

\subsection{Open Sound Control}

OSC Open Sound Control is a protocol of communication between electronic devices across a network. OSC transports messages containing data among computers and devices sharing musical parameter information in the embedded system. This communication receives the messages using the User Data Protocol UDP setting a localhost IP and the port to transmit the information over the network. The basic elements in an OSC message consist of two elements: firstly, the symbolic address and message name; secondly, the data package of the message (Wright \& Freed, 1997, p. 153).

OSC has been widely used in the communication of digital interfaces in apps for smart devices such as mobile phones and tablets, with the purpose of open interaction 
possibilities between sound creators and multimedia devices. OSC protocol promoted the creation of music in a different way than had been seen before; now a person can manipulate musical parameters just by using finger movements in the screen of their gadgets to participate in a performance or to process sound to compose.

This new approach entailed a change of paradigm from a studio-focused system with specialized equipment to a musical interface that can be carried in the pocket using the smart devices features such as touch screens, gyroscopes and cameras to process sound and to create music.

\section{System Components}

This research project created an interactive music system consisting of a smartphone app using an OSC controller and a graphical user interface (GUI) in MaxMSP $^{4}$. The main objective of the system is to control and manipulate musical parameters with an educative purpose. This system was used to teach basic concepts of sound and electroacoustic music to children aged from 6 to 15 years old.

Today there is a plethora of applications that use the OSC protocol to implement control interfaces on mobile devices, by simply searching the most popular application galleries we can find many options for both paid and free control interfaces. Due to the nature of the project, we needed an application to be simple and lightweight enough so that it could be run on modest phones.

To develop the interactive system used in this research, an OSC custom-made app was written in Processing ${ }^{5}$, a programming language based on Java. While the GUI was developed in MaxMSP, this interface processes the sound events in the computer and can be controlled using the OSC app (Fig. 1).

\footnotetext{
${ }^{4}$ https://cycling74.com/

${ }^{5}$ Processing is a flexible software sketchbook and a language for learning how to code within the context of the visual arts. For further reference see https://processing.org
} 
Figure 1. Communication System, main interface on the computer (left), router of the local network (center), app on the mobile device (right).

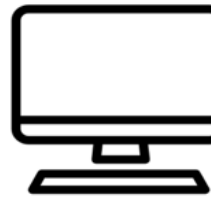

OSC Capable App

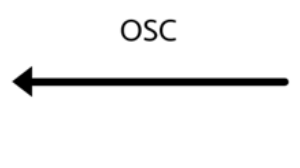

Authors' production.

\subsection{GUI MaxMSP}

The interface in MaxMSP ${ }^{6}$ comprises three main modules of sound processing:

- Audio monitoring

- Mobile OSC controller

- Interactive processing

The first module is used to control the volume of the audio in the interface (in case of live instruments), both the input and the output in 2 or 8 channels. The second one monitors the data sent from the mobile device, while the third one consists of several subinterfaces that process the information of the controller (Fig. 2).

\footnotetext{
${ }^{6}$ The GUI could be run as a standalone application.
} 
Figure 2. Graphic User Interface, modules of monitoring, control and audio processing in MaxMSP.
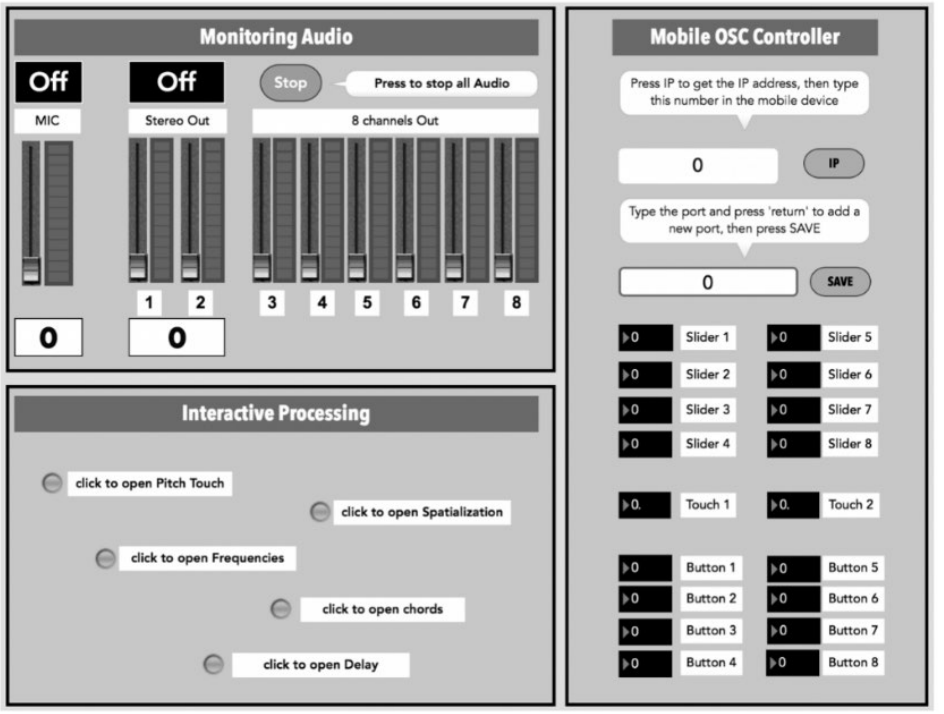

Authors' production.

\subsection{OSC Controller}

The aim of the application is to serve as a control interface for a musical environment developed by Max. The communication is carried out using the Open Sound Control and carrying information through User Data Protocol UDP. We wanted to develop an open source app in this research rather than acquiring licenses from the established interfaces in the market. Using an open source app would allow for easier sharing in the schools and experimenting in the community in a few months.

\subsubsection{Processing Architecture/Design}

Processing is an open source programming language which aims to help artists to integrate new technologies within the context of the visual arts. Easy to implement, it is used as a means of teaching and producing digital design multimedia projects (REAS; FRY, 2014, p. 9). This software also offers a possibility to execute the application on different operating systems including Android for mobile devices and it is possible to send information over OSC directly from the mobile device on the same network. With Processing we achieved a simple interface that was easy to use, but whose configuration remained somewhat technical and also had some additional limitations such as the need to install the necessary libraries manually in the source version of Processing, the need to 
have Java installed in the desktop stand-alone edition and the need to make some configurations prior to the installation of the application in Android.

Despite its limitations, the application could be used, and feedback was received from field application experiences. With all this information it was decided to take a new approach to the problem in which these limitations could be solved. Given the increasingly popular web-oriented technologies, it was decided to explore the possibility of using the web browser to accomplish our purpose. Due to the difficulty of sending information over the network directly from the browser, it was necessary to use WebSocket, which is a communications protocol that enables interaction between a web browser and a web server. However, because OSC and WebSocket are different communications protocols, it is not possible to use both directly, which means that it is necessary to receive and forward information from one to the other. In other words, the information must arrive via WebSocket from the browser to the device and then be processed and redirected over OSC to the end application or device (Fig. 3).

Figure 3 - Web socket route map.

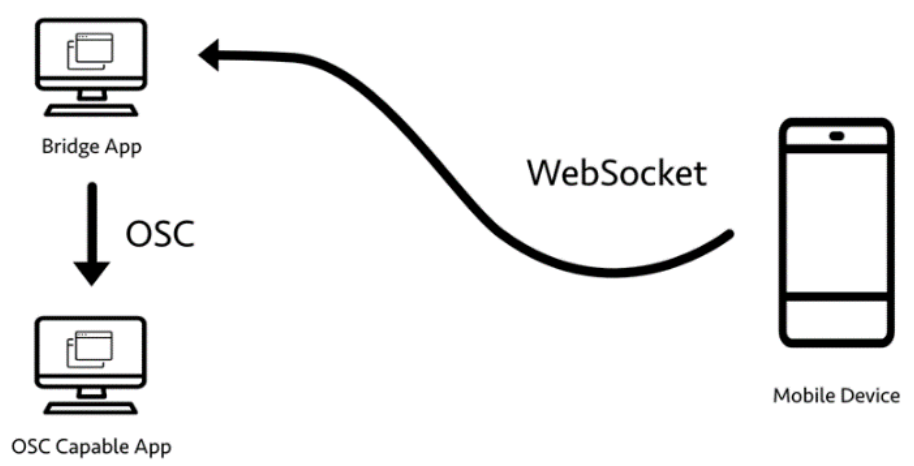

Authors' production.

A desktop application that acted as a bridge between WebSocket and OSC was ideal and also solved the second problem which was to serve the web application so that it could be accessed from a web browser. We used Electron ${ }^{7}$ for this purpose, a framework

\footnotetext{
${ }^{7}$ Electron is an open-source software framework developed and maintained by GitHub. It allows for the development of desktop GUI applications using web technologies. For further reference see: https://www.electronjs.org
} 
to build apps with HTML, CSS, and JavaScript. Using these technologies, we could have a first version of the application running in a short time while also ensuring scalability in the future. To facilitate usability for the user we also used QRCode to open the interface. The final result is a very simple and minimum config UI (Fig. 4).

Figure 4 - QR home screen.

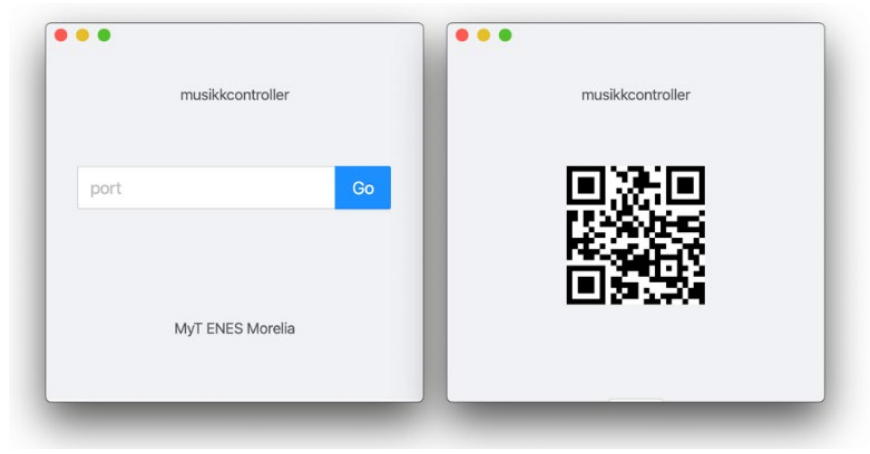

Authors' production.

To use the interface in the web application it is only necessary to scan the abovementioned code to establish the connection automatically and without any configuration, you will be immediately redirected to the web browser (Fig. 5). At the moment it is a simple interface made with HTML and JS, it contains some simple widgets that allow us to interact easily and without the necessity of installing anything ${ }^{8}$, the drawback of this approach could be the unreliable mobile internet network in remote communities.

Figure 5. Web Browser.

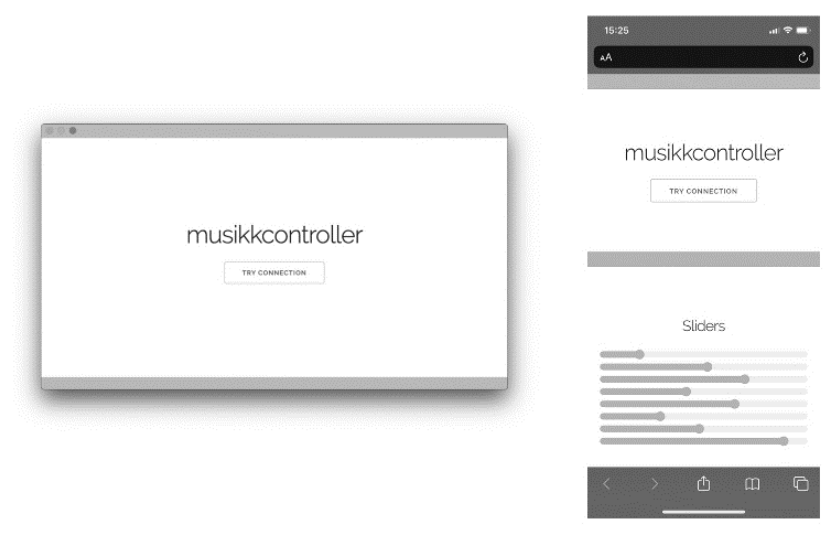

Authors' production.

\footnotetext{
8 For attribution on used libraries please refer to the code which is available on Github.
} https://github.com/roicort/Processing_OSC and https://github.com/roicort/musikkcontroller 


\subsubsection{App GUI controller}

The app on the mobile device consists of five screens (Fig. 6):

1. Main, instructions and general information of the app.

2. Slider, screen with 8 sliders.

3. Touch, uses a graph in two dimensions (X and $\mathrm{Y})$.

4. Buttons, screen with 8 buttons

5. Settings, IP address and port configuration.

Figure 6 - This figure shows the GUI of the OSC controller App. Screen 1 Main, Screen 2 Sliders, Screen 3 Touch, Screen 4 Buttons, and Screen 5 Settings.

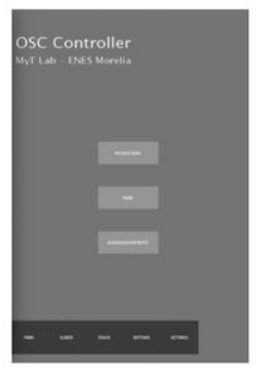

1

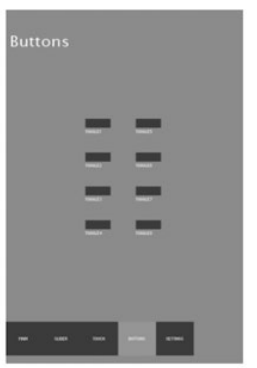

4

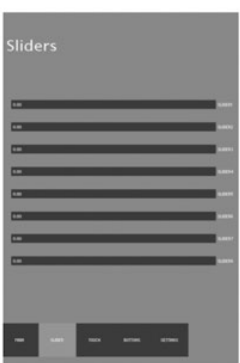

2

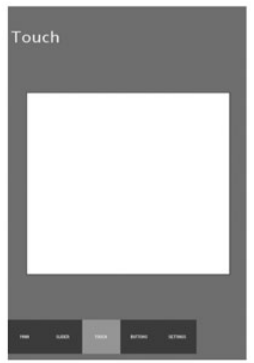

3

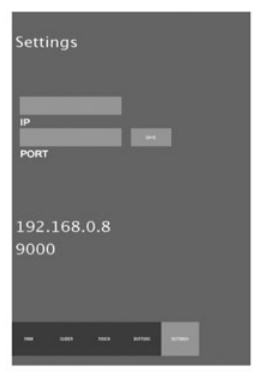

Authors' production.

The first screen of the OSC controller contains information about the instructions and configuration of the app. The process of interaction between the mobile device and the graphic interface in the computer begins when establishing the connection in the local network through the IP address. For this, the graphical user interface in MaxMSP (Fig. 2) obtains automatically the IP of the network to which the computer is connected. After 
that, a Port number is required to establish the connection between the computer and the controller. This data, IP and Port, will have to be entered by the user in the Settings (screen 5) of the OSC Controller (Fig. 6). Once the connection is established, it will be possible to monitor the activity of the OSC Controller in the MaxMSP GUI and process different modules based on musical parameters. For example, the additive synthesis of frequencies in the MaxMSP GUI can be triggered by buttons (screen 4) and its volume controlled by the sliders in the screen 2 of the OSC controller app (Fig. 7).

Figure 7 - Frequencies. The buttons (left) activate the frequencies in the graphic user interface (center) that can change their pitch when the sliders are activated (left) on the OSC controller app.
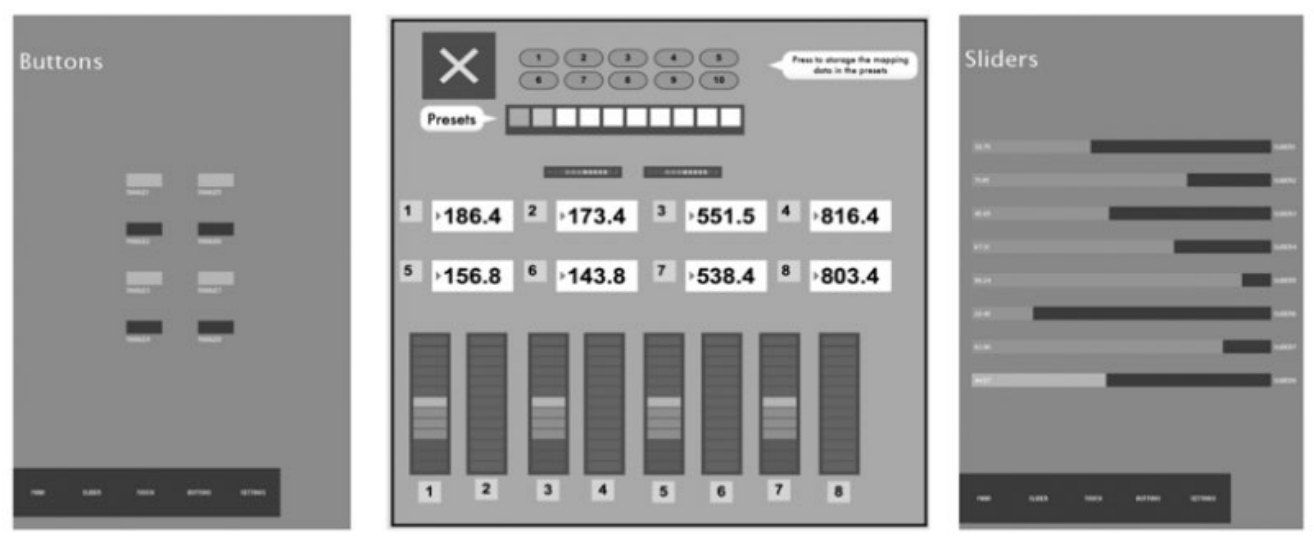

Authors' production.

Pitch and spatialization modules can be modified by sliding the cursor over the surface of the mobile of the touch screen of the OSC Controller, pitch can be transformed, and sound can be diffused into 8 channels (Fig. 8). 
Figure 8. Pitch Touch. The GUI in the computer receives the information of the movements produced by the touch of the app GUI controller (Touch). In the same way, a sound can be diffused into 8 audio channels (spatialization).

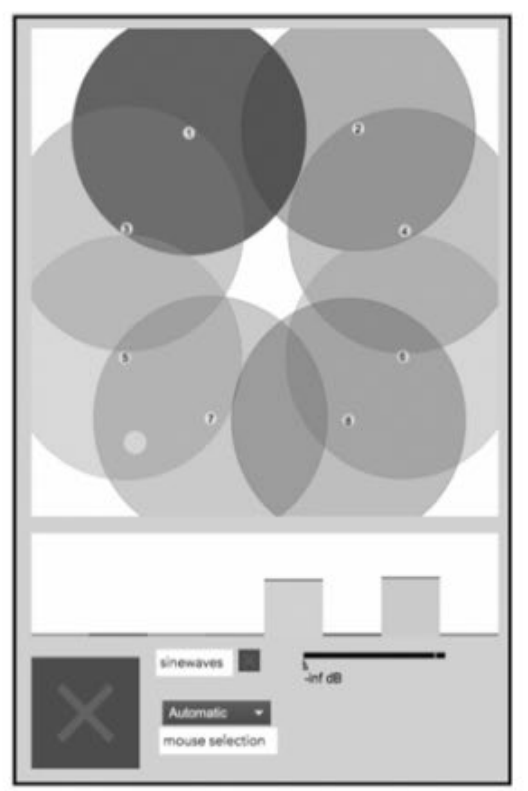

Pitch

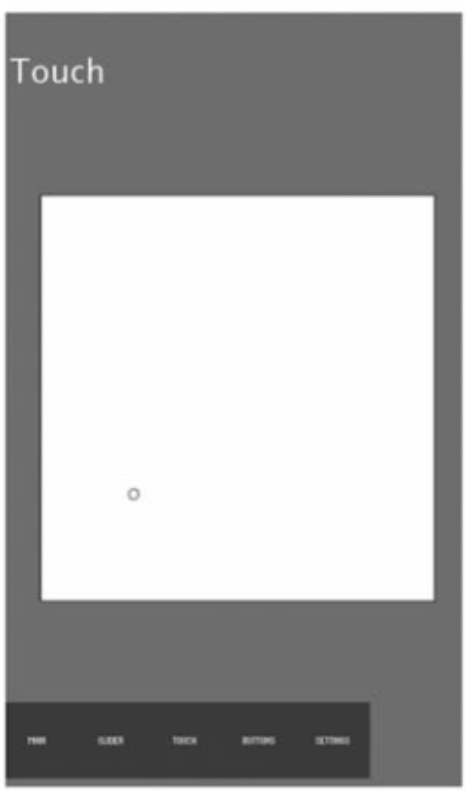

Touch

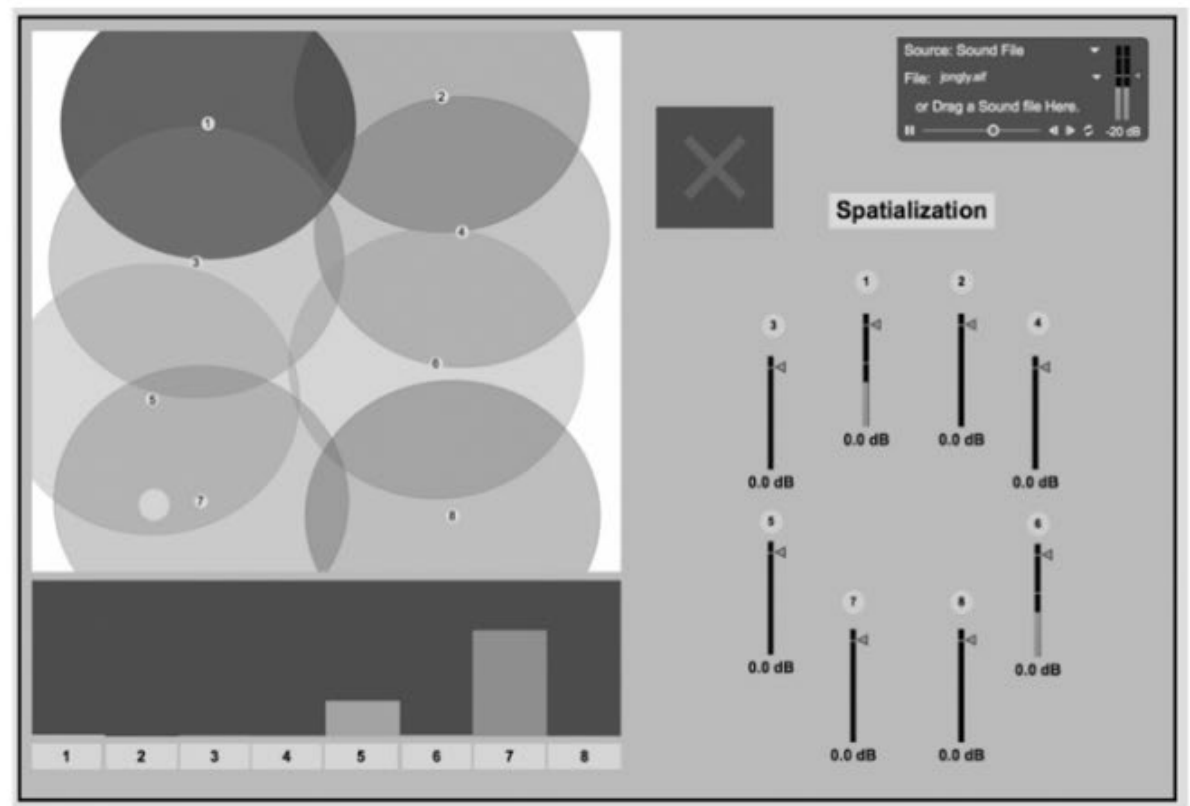

Spatialization

Authors' production. 
Finally, the buttons of the fourth screen in the OSC Controller can trigger a musical interval module in the MaxMSP GUI. A sound can be pitch-shifted creating musical intervals in two octaves, these sounds can be time transformed using the variety of delay modules in the MaxMSP GUI (Fig. 9).

Figure 9 - Delay/Intervals. The buttons (right) activate the intervals or chords in the GUI interface (center) and also the delay process (left).

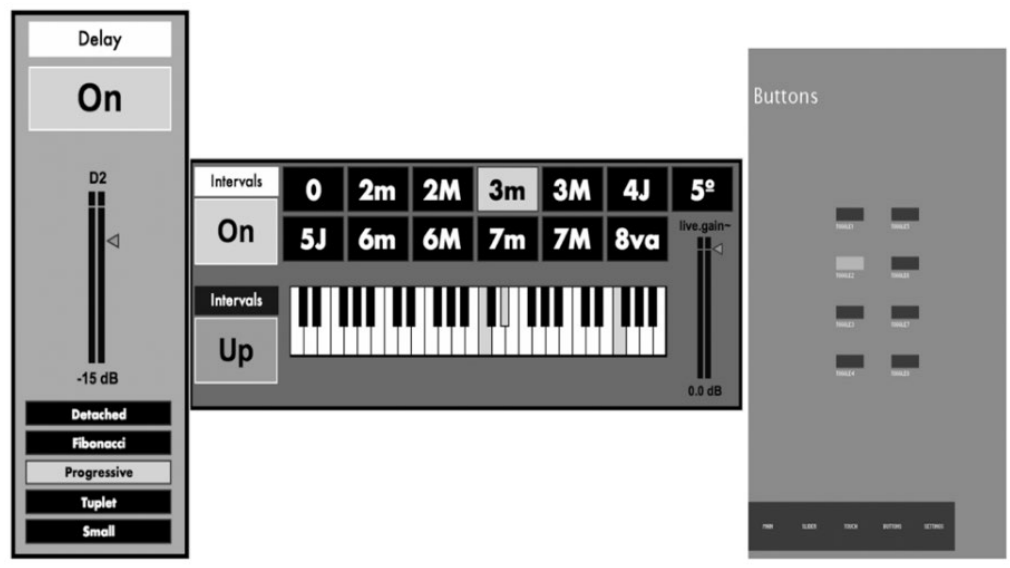

Authors' production.

\section{Use of interactive system in music education}

The interactive system described above was implemented in an electroacoustic music program one day per week during one semester in the primary and secondary school of Tumbisca. We had 60 students in total, 40 children in primary school (6-13 years old) and 20 adolescents in secondary level (13-15 years old). The main objective was to engage children and teenagers with electroacoustic music performance and composition.

Prior to commencing the use of the interactive system, a basic approximation to sound was implemented in order to realize about the sounds of the environment and their properties. Children started to listen more carefully to the soundscapes of the community. This kind of approach led us to use soundscapes as a method of teaching musical parameters. The students quickly began to develop graphic notations to capture the sounds of their surroundings, sharing them with their classmates (Fig. 10). 
Figure 10 - Example of the graphic notation of a soundscape.

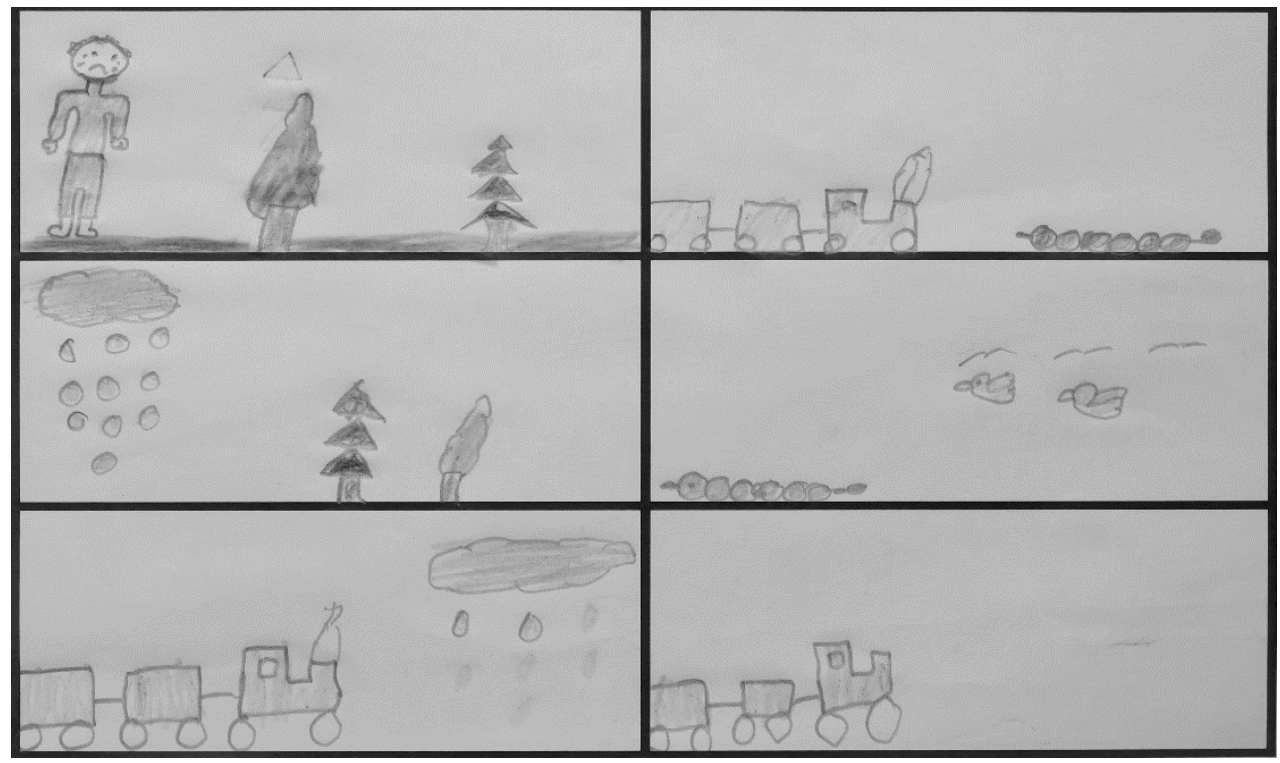

Authors' collection.

After this training, the app was used to explore sound qualities and perform basic routines regarding sound transformations (pitch, duration, timbre, volume) within the interactive system. Also, this helped us to deliver concepts of spatialization, timbre, gesture and texture. All these topics were very hard to deliver to small children, but they started to play with the interactive system more intuitively.

One of the objectives of this project was to engage children with electroacoustic music performance and composition. We designed a course in order to accomplish that goal, at the end of the semester the children could perform their pieces in a concert for all the community. The course involved the participation of a clarinet performer and the use of graphic scores in which the students were able to use the interactive system as a tool for their educative process.

The first stage of the course was to discover and comprehend the basic elements of the sound, they explored timbre, pitch, duration, volume, and space. The second phase consisted in the improvisation of music using non-pitched percussion instruments, this allowed them to perform graphic notations and verbal instructions related to gesture, texture, and structure. The third stage was the main core of the program, in this step the students were asked to compose electroacoustic miniatures using the materials created in former stages. These miniatures were composed using the interactive music system, 
improvisations, and the participation of the clarinet performer where sound was processed and transformed. The final step in this course was the performance of the pieces in a concert in the community ${ }^{9}$, the students were able to perform their pieces in from of an audience of classmates, family, and friends.

\subsection{How the Children Approached Sound and Composing}

The children's compositional approach stemmed from the sounds that they had heard in their everyday environment. One of the electroacoustic miniatures that we created together with the students was based on the sounds of wind and rain. Tumbisca is located in Michoacán, a Mexican state that endures dramatic seasonal contrasts in terms of weather. A hot, dry season occurs from approximately October to May and this contrasts with the rainy season from June to September which brings daily thunderstorms. It became apparent when we were discussing musical parameters such as timbre in the workshops that the children strongly related to the sounds of wind, rain and thunder. During the demonstration of the technical capabilities of the clarinet, the children also perceived connections between the clarinet's sounds and those found in their own environment and this triggered many of the ideas for their compositions. For example, when air sounds were played the children commented that they sounded like the wind and when fast-moving high-pitched notes were played, it reminded them of the sound of bees. Nature and environment also provided a stimulus for their handling of musical structure in the wind and rain piece. The piece began quiet with air sounds and low-pitched material, gradually gathering momentum and energy to reflect the onset of a storm. Other sounds which the children wanted to incorporate into their compositions included sounds from agriculture. As Tumbisca is located in a rural part of Michoacán many of the children's families work in sectors such as beekeeping and logging and therefore sounds such as bees, vehicles and machinery were common features of the compositions.

\subsection{Graphic Scores and Communication}

In order to notate their compositional ideas, the children created graphic scores. The children's often quite literal approach to the preparation of graphic scores enabled them

\footnotetext{
${ }^{9}$ To watch the concert please visit https://duartemario.com/research
} 
to transfer their compositional ideas lucidly which from the performer's perspective brought a lot of advantages. The images they drew demonstrated direct links to sound sources which communicated very effectively the kind of sound that they wanted the clarinetist to achieve. The graphic scores contained clear pictures such as vehicles, animals and raindrops. The children's musical intentions were straightforward to interpret which enabled an effective dialogue between composer and performer and allowed for easy collaboration between all members of the class. For example, in one exercise, the children swapped scores in order to take turns performing each other's pieces and due to their literal approach to the design of graphic scores they were able to clearly identify and reproduce the sounds of the other children's pieces. This unambiguity promoted confidence in their performing and interpretive skills. The characteristics of the children's graphic scores displayed many similarities to the piece Stripsody (1966) by Cathy Berberian which also contains literal graphic representation of objects and words. Beberian's piece Stripsody has been promoted for use in primary education (Hennessy, 1998) and could prove to be a useful tool in the classroom for introducing and developing the concept of graphic scores (Fig. 11).

Figure 11 - Graphic scores examples.
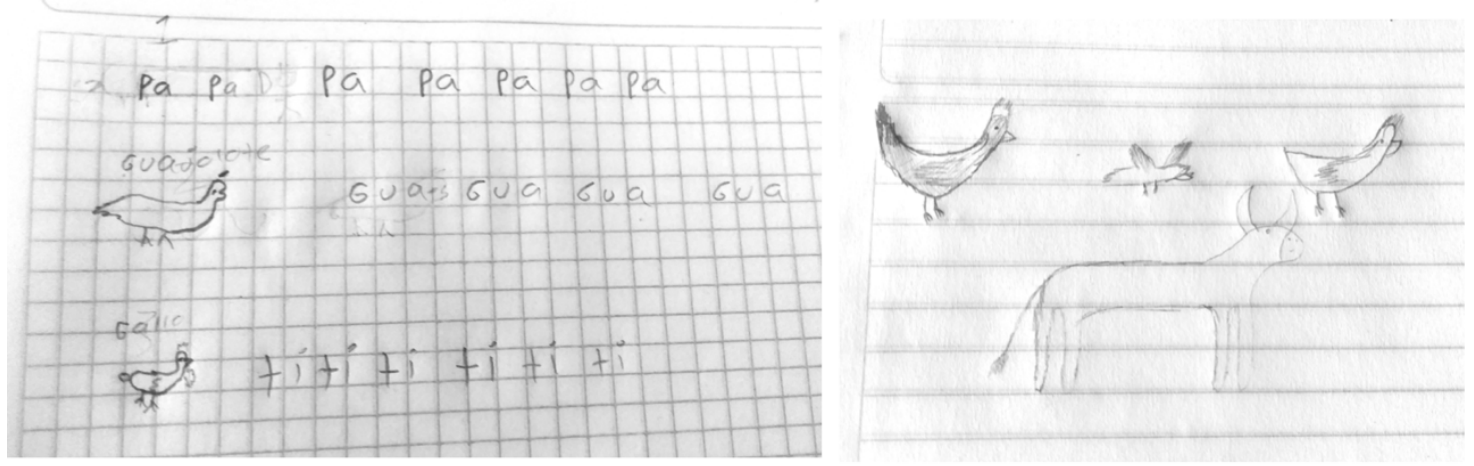

Authors' collection.

\subsection{Ensemble Performance}

When it came to performing the pieces as a group, at first some of the children were reluctant to get involved as it was the first time that they had taken part in a group musical performance and they were unsure of how to approach playing together in an ensemble. One of the first strategies implemented in the performance workshops was to incorporate the idea of call and response. This involved the clarinetist playing a characteristic sound 
or motif such as fast-moving percussive key clicks, air sounds, quiet sustained lowpitched notes or loud high-pitched accented notes. The children would then be encouraged to search for a similar sound that they could create on their own instruments to respond to the sound played by the clarinet. For example, responses to the clarinet's key clicks included tapping the wood of the glockenspiel, tapping the keys of their accordion, shaking a rain stick and tapping the flute. This exercise had the additional advantage of developing perception of musical parameters such as timbre, pitch and dynamics as well as encouraging approaches to improvisation. Once the children were confident responding to the calls of the clarinet, the call and response relationship was then reversed so that the children themselves were then able to suggest their own sounds on their own instruments which the rest of the group would then begin to respond to. This role reversal allowed the children to take control of the direction of the piece, they gained ownership of the performance as well as an understanding of how their own role within the ensemble could fluctuate between that of leader or soloist to that of accompanist (Fig. 12).

Figure 12 - Performance experiences.
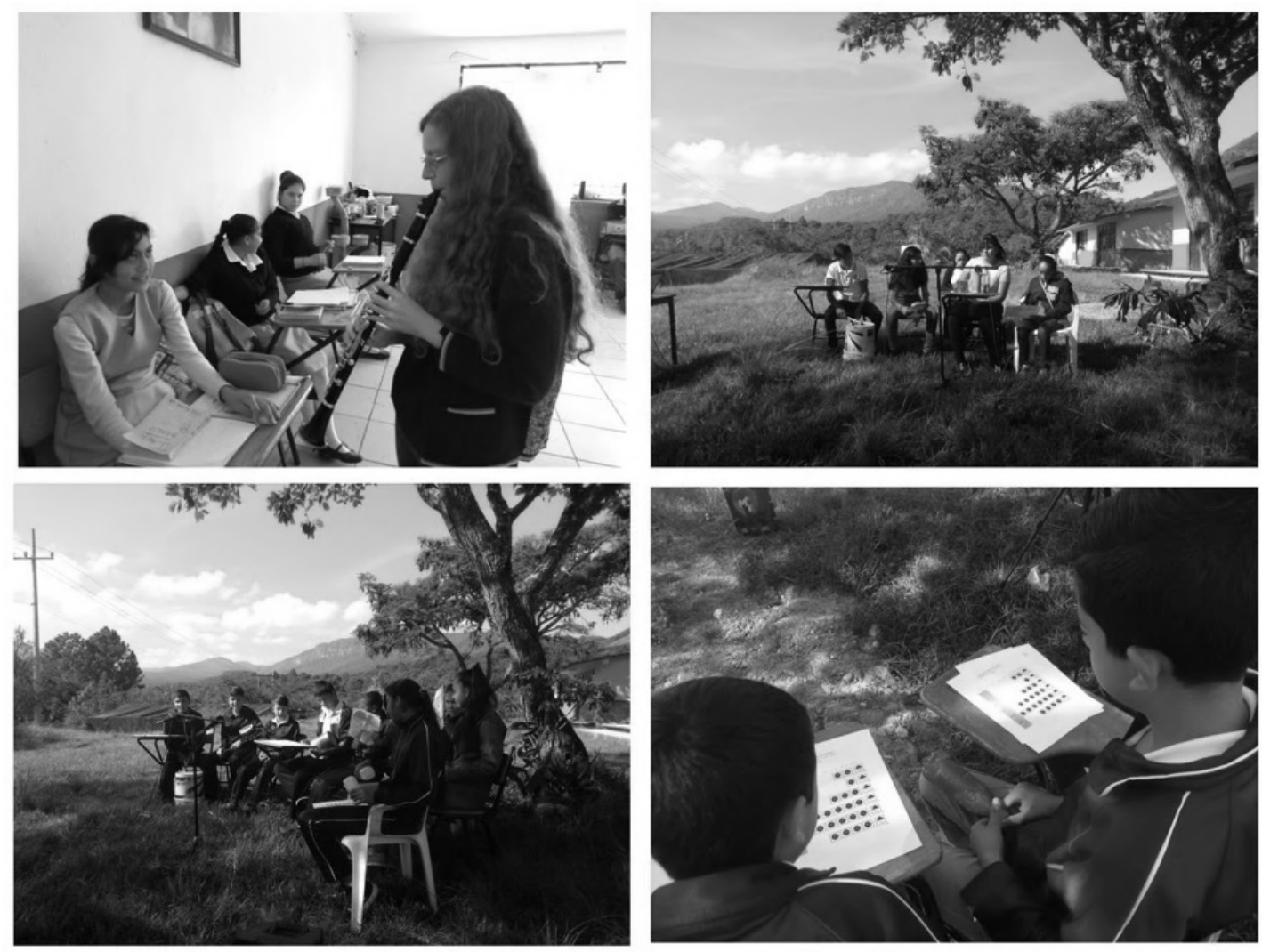

Authors' collection. 
Once the children were comfortable and confident with the exercises of call and response with the ensemble of acoustic instruments, the electronic element was added to the ensemble of acoustic instruments. The addition of the electroacoustic sounds provoked some problems at first. The electronics provided a stark contrast to the sounds of the acoustic instruments and for some children this proved to be a distraction. Some children found it difficult to understand how their acoustic instruments related to the starkly juxtaposing nature of the electroacoustic sounds. To combat this issue, we again implemented the call and response exercise and the students responded to the electroacoustic sounds triggered by the application and gradually they came to view the electronic element as another "instrument" in the ensemble (Fig. 13).

Figure 13 - Sound exploration using the app GUI controller.

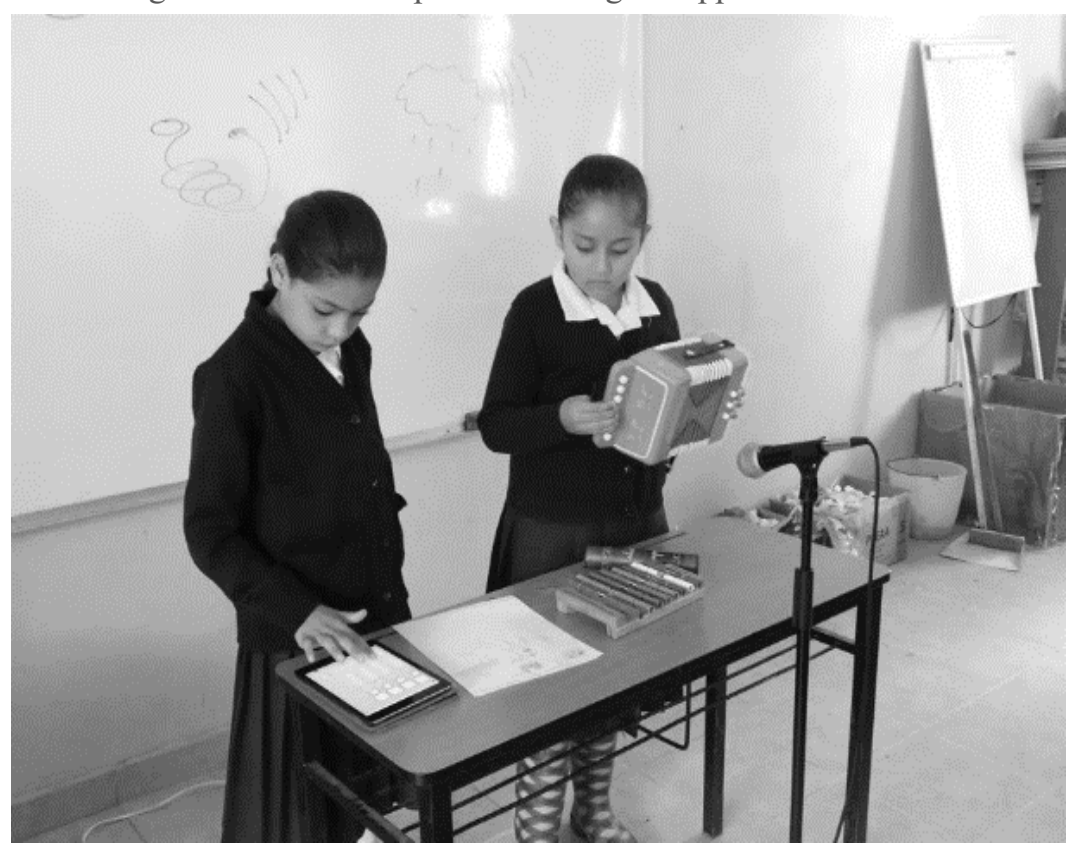

Authors' collection.

\section{Discussion}

In this article we have presented the use of music technology for an educative program in primary and secondary schools in Tumbisca, Michoacán. We developed an interactive music system as an aid for electroacoustic music education in a rural community of the municipality of Morelia. The main objective of this research was to 
enable children's and teenagers' access to electroacoustic music performance and composition and to contribute to the mitigation of the music educational lagging problem in this community.

This project helped us to cover the four key areas of the national arts curriculum content and the recommended time framework for primary and secondary levels. In this research the students participated in a four-stage course in order to compose and perform an electroacoustic miniature. Table 1 shows each stage of the course covered by these four key areas.

Table 1 - Left column shows the four areas to develop in the national arts curriculum. Right column shows the activities developed in the electroacoustic music course in Tumbisca.

\begin{tabular}{|c|c|}
\hline Areas & Activities in the course \\
\hline Artistic practice & $\begin{array}{c}\text { To develop a whole comprehensive artistic } \\
\text { project }\end{array}$ \\
\hline Basic elements & Exploration of musical parameters \\
\hline Expression and Creativity & Creation and performance of EA miniatures \\
\hline Arts and Environment & $\begin{array}{c}\text { Concert } \\
\text { Tomote artistic and social relationships } \\
\text { within the community }\end{array}$ \\
\hline
\end{tabular}

Authors' production.

This course was led by specialists in the field, meaning that an external agent is needed to deliver the course, leaving the issue of external entity dependency unsolved. This is an area of opportunity to cover in further research where teachers from the community will have to be trained in sound organization and interactive music system, only in this way will the project be self-sustaining and will contribute to the mitigation of the music educational lagging problem without external intervention. In this sense the interactive music system and graphic users' interfaces need to be designed to be friendlier to people without IT or music technology backgrounds.

It is important to highlight the social-economic circumstances of Tumbisca, the lack of facilities and resources did not stop the development of this research; on the contrary, we had to come up with creative solutions. We only used a low-tech setup: computer, 
interface, a pair of speakers and microphones, and the use of smart devices (mobile phones/tablets) as controllers. This program could be implemented in rural communities with the same or similar characteristics.

The participation and cooperation of the students is crucial in opening up new perspectives of musical expression. Small children are more open to engaging with new forms of music, the activities for this age group must not be too numerous and must be of short duration. Teenagers in secondary school had more difficulty with engaging due to their ages, this age group had a strong conviction about what music is and it is more difficult to open their music genre boundaries.

\section{Conclusion}

In this research the aim was to facilitate access to exploring sound-control technological devices that allow children to express themselves through sound.

This article showed that the implementation of an interactive music system can be a valuable aid in the classroom in order to deliver electroacoustic music lessons. The use of mobile devices helped to attract people who otherwise would not have been able to access musical education, more specifically, electroacoustic music. This high level of accessibility opened up a new possibility to deliver music courses and interaction with new audiences.

This paper concludes that sound exploration can be very helpful in delivering pedagogical objectives of arts curriculums where communities have a lack of facilities and resources. The inherent language of electroacoustic music is open to different approaches to sound organisation, all sounds can be part of a music composition, and these features placed electroacoustic music in a favoured position that could be exploited in rural schools with music education disadvantage. In the case of Mexico, the aims and objectives of the national art curriculum can be covered using electroacoustic music. 


\section{Acknowledgments and Funding}

Comunidad de Tumbisca, Municipio de Morelia, Michoacán de Ocampo.

Escuela Primaria 16DPR 0979B “20 de Noviembre”, Profra. Eloísa Campos.

Escuela Secundaria ESTV 16819 "Simón Cortez Vieyra", Professors: Sigfrido Lara, Nahúm Ramírez y Leonardo Chávez Juárez.

This research was supported by the postdoctoral scholarship programme of DGAPA, UNAM.

This research is part of the PAPIIT IA401218 programme ENES Morelia, UNAM.

This project was funded by PADID 2018 CENART, FONCA.

"Este texto es parte del proyecto de investigación apoyado por el programa de becas posdoctorales en la UNAM del Programa de Fortalecimiento Académico de la DGAPA"

"Este texto es parte del proyecto de investigación apoyado por el programa PAPIIT IA401218 (ENES, Morelia, UNAM)."

\section{References}

BACKLUND, A. The Definition of System. Kybernetes, v. 29 n. 4, p. 444-451, jun. 2000.

BOULEZ, P. Technology and the Composer. In: Emmerson, S. The Language of Electroacoustic Music. London: The Macmillan Press Ltd., 1986. 5-14.

HENNESSY, S. Coordinating music across the primary school. London: Farmer Press, 1998.

INSTITUTO Nacional de Estadística y Geografía. Encuesta intercensal 2015. Ciudad de México, MX: INEGI, 2015.

LANDY, L. Making Music with Sounds. Abingdon: Routledge, 2012.

LAROSE, D. M.; BURNS, K. J.; CHUPKA, Z. D. 2014. Available at $<$ http://digitalcommons.wpi.edu/iqp-all/258 >. Date of access: 3 jun. 2020.

MANZO, J. V. Electro-acoustic musically interactive room EAMIR. 2007. Available at $<$ http://www.eamir.org/ >. Date of access: 3 jun. 2020.

MANZO, J. V. Max/MSP/Jitter for Music: A practical guide to developing interactive music systems. New York, NY: Oxford University Press, 2011.

MASU, R.; CONCI, A.; CORE, C.; ANGELI, A.; MORREALE, F. Robinflok: A polyphonic algorithmic composer for interactive scenarios with children. In: Proceedings of the 14th sound and music computing conference. Espoo, Finland: SMCC, 2017. 127-32. 
MUSIC Maze, Birmingham Contemporary Music Group. 2020. Available at < https://www.bcmg.org.uk/music-maze>. Date of access: 3 jun. 2020.

REAS, C.; FRY, B. Processing: A Programming Handbook for Visual Designers and Artists. London, UK: The MIT Press, 2014.

REGENMORTEL, H. Eersteklasconcerten: a different look at music participation of children in concert halls. In: Proceedings of the 8th Conference of the European Network of Music Educators and Researchers of Young Children. Cambridge, UK: MERYC2017, 2017, p. 93-100.

SECRETARÍA de Educación Pública. Plan y programas de estudio para la educación básica. Ciudad de México, MX: sep. 2017.

THE MEXICAN CENTRE for Music and Sonic Arts CMMAS. 2020. Available at < http://cmmas.org/as/ >. Date of access: 3 jun. 2020.

TOBIAS, E. Let's Play! Learning music through video games and virtual worlds. In: McPherson, G. and Welch, G. Creativities, Technologies, and Media in Music Learning and Teaching: An Oxford Handbook of Music Education, v. 5. New York: Oxford University Press, 2018, p. $217-$ 235.

WINKLER, T. Strategies for Interaction: Computer Music, Performance, and Multimedia. In: Proceedings of the 1995 Connecticut College Symposium on Arts and Technology. Connecticut, USA: SAT, 1995, p. 1-4.

WRIGH, M. Freed, A.; MOMENI, A. Open Sound Control: State of the Art 2003. In: Proceedings of the 2003 Conference on New Interfaces for Musical Expression. Montreal, Canada: NIME, 2003, p. 153-159. 